\title{
Analisis Portofolio dalam Investasi Saham Pada Pasar Modal
}

\author{
${ }^{1}$ Amir Tjolleng, ${ }^{2}$ Tohap Manurung \\ ${ }^{2}$ Jurusan Matematika, Fakultas MIPA, Universitas Sam Ratulangi, kris_ton79@yahoo.com
}

\begin{abstract}
Investors who invest in shares in the capital market would consider two things: the level of profit and loss or risk level. Expected return is the return expected by investors in the future and are uncertain (uncertainty). Return expectations and risk level has a positive relationship. The greater the risk of a security, the greater the expected benefits, and the smaller the risk of the securities, the smaller the profits. Investors would want a high profit and low risk, but it is not likely to happen for sure. In this case we can use the analysis of portfolio theory of Harry Markowitz, proposed mathematical model to find the right solution. The principle of this model is to form a diversified stock and with some portfolio stock. The goal is to minimize the risk to a certain level of profit or profit-maximizing level with certain risks. Iinvestors can also determine the allocation of funds to be invested in a portfolio of shares. So that each investor will obtain an efficient portfolio choice and optimal.
\end{abstract}

Keywords: Portofolio theory, return

\begin{abstract}
Abstrak
Investor yang berinvestasi saham di pasar modal akan mempertimbangkan dua hal yaitu tingkat keuntungan dan tingkat kerugian atau resiko. Expected return adalah return yang yang diharapkan oleh investor di masa mendatang dan bersifat tidak pasti (uncertainty). Ekpektasi return dan tingkat resiko mempunyai hubungan yang positif. Semakin besar resiko suatu sekuritas, semakin besar return yang diharapkan, dan sebaliknya. Investor tentu menginginkan keuntungan yang tinggi dan resiko yang rendah, namun hal itu tidak mungkin terjadi secara pasti. Dalam hal ini kita dapat menggunakan analisa teori portofolio yang dikemukakan Harry Markowitz dengan model matematikanya untuk mencari solusi yang tepat. Prinsip dari model ini adalah dengan cara diversifikasi saham dengan membentuk berbagai portofolio saham. Tujuannya adalah meminimumkan resiko dengan tingkat keuntungan tertentu atau memaksimumkan tingkat keuntungan dengan resiko tertentu. Disamping itu juga investor dapat menentukan alokasi dana yang harus dïnvestasikan pada portofolio sahamnya. Sehingga setiap investor akan memperoleh pilihan portofolio yang efisien dan optimal.
\end{abstract}

Kata kunci: Teori Portofolio, return

\section{PENDAHULUAN}

Teori portofolio merupakan teori yang berhubungan mengenai pengembalian portofolio yang diharapkan dan tingkat resiko portofolio yang dapat diterima, serta menunjukkan cara pembentukan portofolio yang optimal. Teori portofolio ini saling berkaitan dengan teori pasar modal yang berdasarkan pada pengaruh keputusan investor terhadap harga sekuritas serta menunjukkan hubungan yang seharusnya terjadi antara pengembalian dan resiko sekuritas jika investor membentuk portofolio yang sesuai dengan teori portofolio.

Tingkat pengembalian yang diharapkan (expected return) adalah return yang yang diharapkan akan diperoleh oleh investor di masa mendatang dan sifatnya belum terjadi. Dengan adanya ketidakpastian (uncertainty) tersebut, berarti investor akan memperoleh return di masa mendatang yang belum diketahui persis nila inya. Return ekspektasi dan tingkat resiko mempunyai hubungan yang positif. Semakin besar resiko suatu sekuritas, semakin besar return yang diharapkan, dan sebaliknya.

Konsep dari resiko portofolio pertama kali diperkenalkan oleh Harry M. Markowitz. Markowitz menggabungkan beberapa sekuritas tunggal ke dalam bentuk portofolio. Teori portofolio yang dikemukakan Markowitz dikenal dengan model Markowitz, memberikan suatu cara bagaimana berinvestasi dengan efisien dan optimal., yaitu dengan membentuk portofolio optimal.

Tujuan membentuk portofolio optimal adalah untuk memenuhi prinsip dalam berinvestasi "Memperoleh imbal hasil (return) pada tingkat yang dikehendaki dengan resiko yang paling minimum". Harry Markowitz mengemukakan model matematik untuk menjawab permasalahan tersebut [1]. 
Salah satu pengukur resiko ada lah deviasi standar atau varian yang merupakan kuadrat dari deviasi standar. Resiko yang diukur dengan ukuran ini mengukur resiko dari seberapa besar nilai tiap-tiap item menyimpang dari rata-ratanya. Resiko portofolio juga dapat diukur dengan besarnya deviasi standar atau varian dari nilai return-return sekuritas tunggal di dalamnya.

\section{Dive rsifikasi}

Untuk meminimumkan resiko, perlu dilakukan diversifikasi dalam berinvestasi, yaitu membentuk portofolio atau meng-investasikan dana tidak hanya disatu asset saja melainkan kebeberapa asset. Permasalahannya adalah berapa besar proporsi dana harus diinvestasikan pada masing-masing asset agar diperoleh tingkat imbal hasil yang dikehendaki dengan resiko yang paling minimum. Diversifikasi ini sangat penting untuk investor, karena dapat meminimumkan resiko tanpa harus mengurangi return yang diterima. Bagian dari resiko sekuritas yang dapat dihilangkan dengan membentuk portofolio yang well-diversified disebut dengan resiko yang dapat didiversifikasikan (diversifiable risk) atau resiko perusahaan (company risk) atau resiko spesifik (specific risk) atau resiko unik (unique risk) atau resiko yang tidak sistematik (unsystematic risk). Sebaliknya, resiko yang tidak dapat didiversifikasikan oleh portofolio disebut dengan nondiversifiable risk atau resiko pasar (market risk) atu resiko umum (general risk) atau resiko sistematik (systematic risk). Resiko ini terjadi karena kejadian-kejadian di luar kegiatan perusahaan, seperti inflasi, resesi, dan lain sebagainya.

\section{Pemilihan Portofolio}

Investor yang berfikir rasional akan memilih portofolio yang optimal. Portofolio optimal dapat ditentukan dengan menggunakan model Markowitz atau model indeks tunggal. Untuk menentukan portofolio yang optimal dengan model-model ini yang pertama kali dibutuhkan adalah menentukan portofolio yang efisien. Karena tiap-tiap investor memiliki kurva berbeda, portofolio akan berbeda untuk masing-masing investor. Investor yang lebih menyukai resiko akan memilih portofolio dengan return yang tinggi dengan membayar resiko yang juga lebih tinggi dibandingkan dengan investor yang kurang menyukai resiko. Portofolio yang efisien didefinisikan sebagai portofolio yang memberikan return ekspektasi terbesar dengan resiko yang sudah tertentu atau memberikan resiko terkecil dengan return ekspektasi yang sudah tertentu. Portofolio yang efisien ini dapat ditentukan dengan memilih tingkat return ekspektasi tertentu dan kemudian meminimumkan resikonya atau menentukan tingkat resiko yang tertentu kemudian memaksimumkan return ekspektasinya. Investor yang rasional akan memilih portofolio yang efisien ini karena merupakan portofolio yang dibentuk dengan mengoptimalkan satu dari dua dimensi, yaitu return ekspektasi atau resiko portofolio.

\section{Asumsi Portofolio Optimal Berdasarkan Model Markowitz}

Untuk menentukan portofolio yang optimal Model Markowitz menggunakan asumsiasumsi sebagai berikut :

- Waktu yang digunakan hanya satu periode.

- Tidak ada biaya transaksi.

- Preferensi investor hanya didasarkan pada return ekspektasi dan resiko dari portofolio.

- Tidak ada pinjaman dan simpanan bebas resiko.

Return dan standar deviasi dari Portofolio (banyak Aset)

Untuk portofolio dari beberapa aset, return dari aset dikarakterisasi oleh mean, variansi dan kovarians inya.

- Rata-rata Return

\begin{tabular}{|l|c|c|c|c|}
\hline Asset & 1 & 2 & $\cdots$ & $\mathrm{n}$ \\
\hline Mean Return & $\bar{r}_{1}$ & $\bar{r}_{2}$ & $\cdots$ & $\bar{r}_{n}$ \\
\hline
\end{tabular}

- Variansi dan Kovariansi 


\begin{tabular}{|c|cccc|}
\hline & $r_{1}$ & $r_{2}$ & $\cdots$ & $r_{n}$ \\
\hline$r_{1}$ & $\sigma_{1}^{2}$ & $\sigma_{12}$ & $\cdots$ & $\sigma_{1 n}$ \\
$r_{2}$ & $\sigma_{21}$ & $\sigma_{2}^{2}$ & $\cdots$ & $\sigma_{2 n}$ \\
$\vdots$ & $\vdots$ & $\vdots$ & $\ddots$ & $\vdots$ \\
$r_{n}$ & $\sigma_{n 1}$ & $\sigma_{n 2}$ & $\cdots$ & $\sigma_{n}^{2}$ \\
\hline
\end{tabular}

Anggaplah bahwa portofolio dengan $w_{i}$ sebagai bobot nilai proporsi yang diinvestasikan dalam aset. Maka :

$$
\sum_{i=1}^{n} w_{i}=1
$$

Secara umum pada portofolio banyak aset berlaku :

- Return portofolio

$$
\tilde{r}_{p}=w_{1} \tilde{r}_{1}+w_{2} \tilde{r}_{2}+\cdots+w_{n} \tilde{r}_{n}=\sum_{i=1}^{n} w_{i} \tilde{r}_{i} .
$$

- Expected return dari portofolio

$$
\bar{r}_{p}=\mathrm{E}\left[r_{p}\right]=w_{1} \bar{r}_{1}+w_{2} \bar{r}_{2}+\cdots+w_{n} \bar{r}_{n}=\sum_{i=1}^{n} w_{i} \bar{r}_{i} .
$$

- Variansi dari return portofolio

dimana $\sigma_{i i}=\sigma_{i}^{2}$.

$$
\sigma_{p}^{2}=\operatorname{Var}\left[\tilde{r}_{p}\right]=\sum_{i=1}^{n} \sum_{j=1}^{n} w_{i} w_{j} \sigma_{i j}
$$

- Standar deviasi darı retun portofolio

$$
\sigma_{p}=\sqrt{\operatorname{Var}\left[\tilde{r}_{p}\right]}=\sqrt{\sigma_{p}^{2}}
$$

Variansi dari return portofolio dapat dihitung dengan menjumlahkan semua entri pada tabel di bawah ini :

\begin{tabular}{|c|cccc|}
\hline & $w_{1} r_{1}$ & $w_{2} r_{2}$ & $\cdots$ & $w_{n} r_{n}$ \\
\hline$w_{1} r_{1}$ & $w_{1}^{2} \sigma_{1}^{2}$ & $w_{1} w_{2} \sigma_{12}$ & $\cdots$ & $w_{1} w_{n} \sigma_{1 n}$ \\
$w_{2} r_{2}$ & $w_{2} w_{1} \sigma_{21}$ & $w_{2}^{2} \sigma_{2}^{2}$ & $\cdots$ & $w_{2} w_{n} \sigma_{2 n}$ \\
$\cdots$ & $\vdots$ & $\vdots$ & $\ddots$ & $\vdots$ \\
$w_{n} r_{n}$ & $w_{n} w_{1} \sigma_{n 1}$ & $w_{n} w_{2} \sigma_{n 2}$ & $\cdots$ & $w_{n}^{2} \sigma_{n}^{2}$ \\
\hline
\end{tabular}

\section{Batasan Portofolio (Portofolio Frontier) tanpa Aset Bebas Resiko}

Penyelesaian masalah optimasi portofolio dapat dilakukan dengan cara berikut :

Dengan menggunakan notasi matriks, kita dapat menuliskan kembali masalah optimasi portofolio sebagai :

$$
\begin{aligned}
& \underset{\mathbf{w}}{\operatorname{Minimize}} \sigma_{p}^{2}=\mathbf{w}^{\top} \mathbf{V} \mathbf{w} \\
& \text { subject to (1) } \mathbf{w}^{\top} \mathbf{1}=1 \\
& \text { (2) } \mathbf{w}^{\top} \overline{\mathbf{r}}=\bar{r}_{p}
\end{aligned}
$$


Untuk menyelesaikan kendala-kendala masalah optimasi di atas, kita menggunakan metode Lagrange

$$
L=\mathbf{w}^{\top} \mathbf{V} \mathbf{w}+\lambda\left(1-\mathbf{w}^{\top} \mathbf{1}\right)+\theta\left(\bar{r}_{p}-\mathbf{w}^{\top} \overline{\mathbf{r}}\right)
$$

Dimana $\lambda \operatorname{dan} \theta$ adalah dua parameter yang disebut pengali Lagrange.

Keadaan optimal diberikan me lalui persamaan berikut :

$$
\frac{\partial L}{\partial \mathbf{w}}=2 \mathbf{V} \mathbf{w}-\lambda \mathbf{1}-\theta \overline{\mathbf{r}}=0 .
$$

Asumsikan bahwa tak singular. Maka :

$$
\mathbf{w}=\mathbf{V}^{-1}\left(\frac{\lambda}{2} \mathbf{1}+\frac{\theta}{2} \overline{\mathbf{r}}\right)
$$

Dua kendala, $\mathbf{w}^{\top} \mathbf{1}=1$ dan $\quad \mathbf{w}^{\top} \overline{\mathbf{r}}=r_{p}$ nemberikan dua persamaan untuk $\lambda \operatorname{dan} \theta$ :

$$
\begin{gathered}
\bar{r}_{p}=a_{2} \frac{\lambda}{2}+a_{1} \frac{\theta}{2} \\
\text { dimana } \quad a_{1}=\overline{\mathbf{r}}^{\top} \mathbf{V}^{-1} \overline{\mathbf{r}}, \quad a_{2}=\overline{\mathbf{r}}^{\top} \mathbf{V}^{-1} \mathbf{1}, \quad a_{3}=\mathbf{1}^{\top} \mathbf{V}^{-1} \mathbf{1}
\end{gathered}
$$$$
1=a_{3} \frac{\lambda}{2}+a_{2} \frac{\theta}{2}
$$

Dengan menyelesaikan $\lambda$ dan $\theta$, kita memperoleh :

$$
\frac{\lambda}{2}=\frac{1}{D}\left(a_{1}-a_{2} \bar{r}_{p}\right) \text { and } \frac{\theta}{2}=\frac{1}{D}\left(-a_{2}+a_{3} \bar{r}_{p}\right)
$$

dimana

$$
D=a_{1} a_{3}-a_{2}^{2}
$$

Substitusi semua yang telah diperoleh untuk mendapatkan solusi batasan portofolio dengan return yang diharapkan :

$$
\begin{aligned}
& \mathbf{w}=\frac{1}{D}\left(a_{1} \mathbf{V}^{-1} \mathbf{1}-a_{2} \mathbf{V}^{-1} \overline{\mathbf{r}}\right)+\frac{1}{D}\left(a_{3} \mathbf{V}^{-1} \overline{\mathbf{r}}-a_{2} \mathbf{V}^{-1} \mathbf{1}\right) \bar{r}_{p} . \\
& \mathbf{w}_{0}=\frac{1}{D}\left(a_{1} \mathbf{V}^{-1} \mathbf{1}-a_{2} \mathbf{V}^{-1} \overline{\mathbf{r}}\right) \\
& \left.\mathbf{w}=\mathbf{w}_{0}+\left(\mathbf{w}_{1}-\mathbf{w}_{0}\right) \bar{r}_{p}{ }^{-1} \overline{\mathbf{r}}\right)+\frac{1}{D}\left(a_{3} \mathbf{V}^{-1} \overline{\mathbf{r}}-a_{2} \mathbf{V}^{-1} \mathbf{1}\right) \\
& \mathbf{w}_{p}=\mathbf{w}_{0}\left(1-\bar{r}_{p}\right)+\mathbf{w}_{1} \bar{r}_{p} .
\end{aligned}
$$

Variansi dari batasan portofolio sebagai :

$$
\sigma_{p}^{2}=\left(1-\bar{r}_{p}\right)^{2} \mathbf{w}_{0}^{\top} \mathbf{V w}_{0}+2 \bar{r}_{p}\left(1-\bar{r}_{p}\right) \mathbf{w}_{0}^{\top} \mathbf{V} \mathbf{w}_{1}+\bar{r}_{p}^{2} \mathbf{w}_{1}^{\top} \mathbf{V w}_{1} .
$$

Standar ceviası ualı valasall portolono sevagal $[\angle]$ :

$$
\sigma_{p}=\sqrt{\left(1-\bar{r}_{p}\right)^{2} \mathbf{w}_{0}^{\top} \mathbf{V} \mathbf{w}_{0}+2 \bar{r}_{p}\left(1-\bar{r}_{p}\right) \mathbf{w}_{0}^{\top} \mathbf{V w}_{1}+\bar{r}_{p}^{2} \mathbf{w}_{1}^{\top} \mathbf{V} \mathbf{w}_{1}} .
$$

\section{METODE PENELITIAN}

a. Sumber data pada bursa efek Indonesia (BEI) yang di ambil dari internet) selama 3 tahun (Mei 2009-Februari 2012) [3]. Aset yang dipilih adalah PT. Tambang Batubara Bukit Asam (Persero) Tbk (PTBA. JK), PT. Semen Gresik (Persero) Tbk (SMGR. JK), dan PT. Telekomunikasi Indonesia Tbk (Persero) (TLKM. JK) 
b. Data yang diambil adalah data sekunder harga penutupan (Close Price) per bulan selama 3 tahun. Dari data harga saham yang diambil akan ditentukan return per periode setiap awal bulan masa perdagangan mulai Mei 2009-Februari 2012. Masing-masing saham akan ditentukan portofolio yang mungkin dari ketiga saham. Dari portofolia akan ditentukan portofolio yang paling efektif berdasarkan tingkat keuntungan dan resiko.

\section{HASIL DAN PEMBAHASAN}

\section{Memilih Portofolio yang Optimal dari Tiga Aset}

Tabel berikut ini adalah return dan deviasi standar yang menyajikan sampel piliha acak dari 3 aset saham yang aktif di pasar modal Indonesia yakni PT. Tambang Batubara Bukit Asam (Persero) Tbk (PTBA. JK), PT. Semen Gresik (Persero) Tbk (SMGR. JK), dan PT. Telekomunikasi Indonesia Tbk (Persero) (TLKM. JK) yang ada pada pasar modal Indonesia (Lampiran).

Tabel 1. Rata-rata dan deviasi standar 3 aset

\begin{tabular}{|c|c|c|}
\hline Nama Saham & Rata-Rata & De viasi Standar \\
\hline PTBA.JK & 0.003 & 0.194 \\
\hline SMGR.JK & 0.01 & 0.182 \\
\hline TLKM.JK & -0.015 & 0.175 \\
\hline
\end{tabular}

Berdasarkan data di atas, akan dikombinasikan menjadi 7 jenis portofolio (termasuk saham tunggal). Dengan menggunakan formula pada bagian 2.1, masing masing portofolio mempunyai nilai rata-rata dan deviasi standar seperti pada tabel berikut.

Tabel 2. No mor Portofolio dengan nilai rata-rata serta deviasi standar

\begin{tabular}{|c|c|c|c|}
\hline $\begin{array}{c}\text { Portofolio } \\
\text { Nomor }\end{array}$ & Komposisi Portofolio & $\begin{array}{c}\text { Rata-Rata Tingkat } \\
\text { Ke untung an }\end{array}$ & $\begin{array}{c}\text { Deviasi } \\
\text { Standar }\end{array}$ \\
\hline $\mathbf{P}_{\mathbf{1}}$ & 1 PTBA.JK & 0,003 & 0,194 \\
\hline $\mathbf{P}_{\mathbf{2}}$ & 1 SMGR.JK & 0,01 & 0,182 \\
\hline $\mathbf{P}_{\mathbf{3}}$ & 1 TLKM.JK & $-0,015$ & 0,175 \\
\hline $\mathbf{P}_{\mathbf{4}}$ & 0,5 PTBA.JK dan 0,5 SMGR.JK & 0,0065 & 0,18 \\
\hline $\mathbf{P}_{\mathbf{5}}$ & 0,5 PTBA.JK dan 0,5 TLKM.JK & $-0,006$ & 0,38 \\
\hline $\mathbf{P}_{\mathbf{6}}$ & $\begin{array}{r}\text { 0,5 SMGR.JK dan 0,5 } \\
\text { TLKM.JK }\end{array}$ & $-0,0025$ & 0,39 \\
\hline $\mathbf{P}_{\mathbf{7}}$ & $\begin{array}{r}\text { 0,33 PTBA.JK } ; 0,33 \text { SMGR.JK } \\
\text { dan 0,5 TLKM.JK }\end{array}$ & $-0,00066$ & 0,18 \\
\hline
\end{tabular}




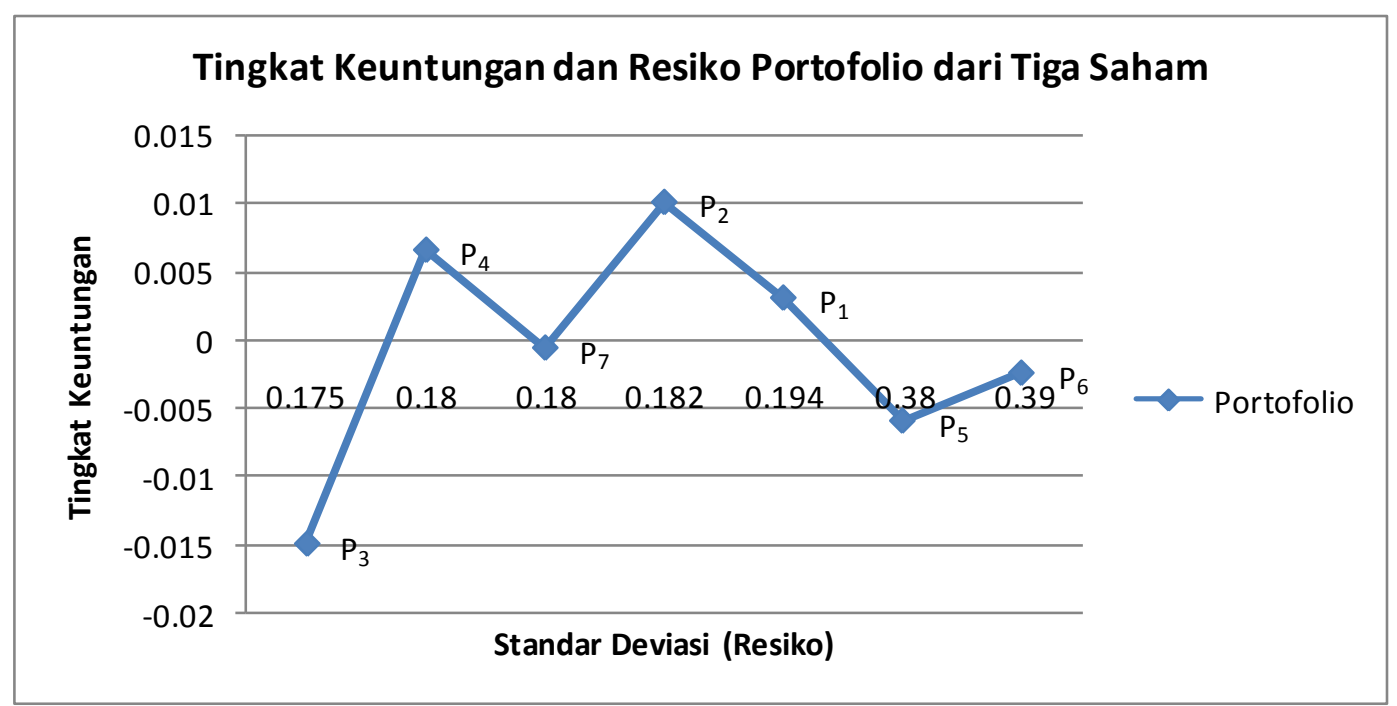

Gambar 1. Ting kat Keuntungan dan Resiko Portofolio

\section{Batasan Portofolio (Portofolio Frontier) tanpa Aset Bebas Resiko dari Tiga Aset}

Pada bagian ini, kita akan menentukan batasan portofolio dari 3 aset dalam bentuk batasan berupa nilai bobotnya untuk memperoleh return tertentu yang diinginkan dalam berinvestasi. Penentuan bobot tersebut akan dilakukan secara manual berdasarkan formulasi yang telah dipaparkan pada bagian 2.2 di atas. Saham yang digunakan yaitu saham PTBA JK., SMGR JK. dan TLKM JK.

Misalkan kita definisikan :

$$
\begin{gathered}
\mathbf{w}=\left(\begin{array}{c}
w_{1} \\
w_{2} \\
\vdots \\
w_{n}
\end{array}\right), \quad \overline{\mathbf{r}}=\left(\begin{array}{c}
\bar{r}_{1} \\
\bar{r}_{2} \\
\vdots \\
\bar{r}_{n}
\end{array}\right), \quad \mathbf{V}=\left(\begin{array}{cccc}
\sigma_{1}^{2} & \sigma_{12} & \cdots & \sigma_{1 n} \\
\sigma_{21} & \sigma_{2}^{2} & \cdots & \sigma_{2 n} \\
\vdots & \vdots & \ddots & \vdots \\
\sigma_{n 1} & \sigma_{n 2} & \cdots & \sigma_{n}^{2}
\end{array}\right)=\mathbf{V}^{\top} \\
\mathbf{w}^{\top}=\left(\begin{array}{llll}
w_{1} & w_{2} & \cdots & w_{n}
\end{array}\right), \quad \overline{\mathbf{r}}^{\top}=\left(\begin{array}{llll}
\bar{r}_{1} & \bar{r}_{2} & \cdots & \bar{r}_{n}
\end{array}\right)
\end{gathered}
$$

$w$ dimana adalah bobot yang akan dicari, $\bar{r}$ adalah rata-rata return dan $V$ adalah covarians dari return aset dalam bentuk matriks.

Selanjutnya, dengan melakukan substitusi pada matriks-matriks di atas berdasarkan data sebelumnya diperoleh : $\bar{r}=\left(\begin{array}{c}0,003 \\ 0,01 \\ -0,015\end{array}\right) \quad \bar{r}^{T}=\left(\begin{array}{lll}0,003 & 0,01 & -0,015\end{array}\right)$

$V=V^{T}=\left(\begin{array}{ccc}0,037 & 0,03 & 0,026 \\ 0,03 & 0,033 & 0,027 \\ 0,026 & 0,027 & 0,03\end{array}\right)$

$V^{-1}$ diperoleh dengan menggunakan program $\mathrm{R}$ seperti berikut ini :

Berdasarkan hasil di atas, diperoleh $V^{-1}$ dengan pembulatan :

$V^{-1}=\left(\begin{array}{ccc}105,7 & -80,2 & -19,4 \\ -80,2 & 175,8 & -88,7 \\ -19,4 & -88,7 & 130\end{array}\right)$ 


$$
a_{1}=0,07 ; a_{2}=-0,24 ; a_{3}=35
$$

\section{$D=2,4$}

$$
w_{0}=\left(\begin{array}{c}
0,02 \\
0,5 \\
0,35
\end{array}\right) \text { dan } w_{1}=\left(\begin{array}{c}
-2,3 \\
43,1 \\
-40
\end{array}\right)
$$

Sehingga diperoleh

$$
\mathbf{w}=\mathbf{w}_{0}+\bar{r}_{p}\left(\mathbf{w}_{1}-\mathbf{w}_{0}\right) \quad r_{0}+\bar{r}_{p}\left(w_{1}-w_{0}\right)=\left(\begin{array}{c}
0,02 \\
0,5 \\
0,35
\end{array}\right)+\overline{r_{p}}\left(\begin{array}{c}
-2,32 \\
42,6 \\
-40,4
\end{array}\right)
$$

Andaikan anda menginginkan $\overline{r_{p}}=50 \%$ maka $w=\left(\begin{array}{c}-1,9 \\ 21,8 \\ -19,9\end{array}\right)$

Misalkan anda memiliki uang \$1 maka :

- Short sell \$-1,9 kekayaan pada saham PTBA.JK

- Belilah $\$ 21,8$ kekayaan pada saham SMGR.JK

- Short sell\$ - 19,9 kekayaan pada saham TLKM.JK

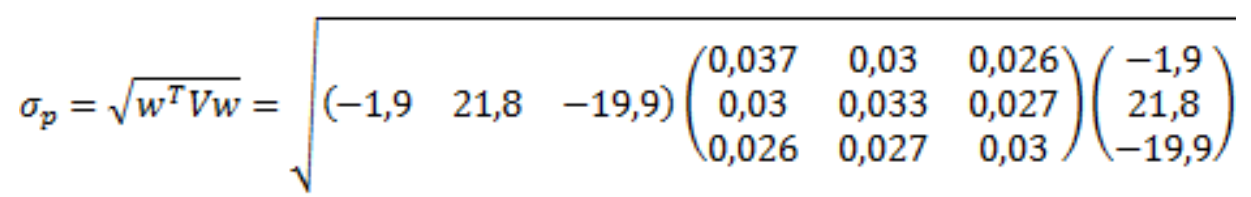

$$
\begin{aligned}
& =\sqrt{3,75}=1,9
\end{aligned}
$$

Andaikan kita menginginkan $\overline{r_{p}}=100 \%$ maka $w=\left(\begin{array}{c}-2,3 \\ 43,1 \\ -40,05\end{array}\right)$

Misalkan anda memiliki uang \$1 maka :

- Short sell\$-2,3 kekayaan pada saham PTBA.JK

- Belilah $\$ 43,1$ kekayaan pada saham SMGR.JK

- Short sell \$-40,05 kekayaan pada saham TLKM.JK

$$
\begin{aligned}
& \sigma_{p}=\sqrt{w^{T} V w}=\sqrt{\left(\begin{array}{lll}
-2,3 & 43,1 & -40,05
\end{array}\right)\left(\begin{array}{ccc}
0,037 & 0,03 & 0,026 \\
0,03 & 0,033 & 0,027 \\
0,026 & 0,027 & 0,03
\end{array}\right)\left(\begin{array}{c}
-2,3 \\
43,1 \\
-40,05
\end{array}\right)} \\
& =\sqrt{15,3}=3,9
\end{aligned}
$$

Dengan menggunakan cara di atas, kita dapat mengubah return yang diinginkan dan memperoleh nilai bobot untuk mas ing-masing saham. 
Jika kita menginginkan return $\overline{r_{p}}=50 \%$ maka resikonya $\sigma_{p}=1,9$. Selanjutnya, jika kita menginginkan return $\overline{r_{p}}=100 \%$ maka resikonya $\sigma_{p}=3,9$.

Berdasarkan hasil yang diperoleh dapat dikatakan bahwa semakin tinggi keuntungan investasi yang kita inginkan maka resikonya juga akan meningkat.

\section{KESIMPULAN}

1. Tujuan membentuk portofolio optimal adalah untuk memenuhi prinsip dalam berinvestasi "Memperoleh imbal hasil (return) pada tingkat yang dikehendaki dengan resiko yang paling minimum". Untuk meminimumkan resiko, perlu dilakukan diversifikasi dalam berinvestasi, yaitu membentuk portofolio atau meng-investasikan dana tidak hanya disatu asset saja melainkan ke beberapa asset.

2. Berdasarkan hasil yang diperoleh dapat dikatakan bahwa semakin tinggi keuntungan investasi yang kita inginkan maka resikonya juga akan meningkat

\section{DAFTAR PUSTAKA}

[1] Husnan, Suad, Dasar-dasar teori Portofolio dan Analisis Sekuritas. Edisi Kedua. Penerbit AMP YKPN, Yogyakarta,1994

[2] Wang, Jiang, Lecture Notes : Portfolio Theory. Fall,2003

[3] http://finance.yahoo.com/ 